\title{
International Journal of Mechanical and Industrial Engineering
}

Volume 2 | Issue 2

Article 3

October 2012

\section{Design and Analysis of Water Motor Vehicle with Electrolysis Process}

\author{
ABHISHEKH KUMAR \\ JIT Borawan (M.P.), S.S.S.I.S.T., Sehore (M.P.), ydvabhishek@gmail.com \\ Ankit Jain \\ Sri Satya Sai Institute of Science \& Technology, Sehore, (M.P.), ankit_mech86@rediffmail.com
}

Follow this and additional works at: https://www.interscience.in/ijmie

Part of the Manufacturing Commons, Operations Research, Systems Engineering and Industrial Engineering Commons, and the Risk Analysis Commons

\section{Recommended Citation}

KUMAR, ABHISHEKH and Jain, Ankit (2012) "Design and Analysis of Water Motor Vehicle with Electrolysis Process," International Journal of Mechanical and Industrial Engineering: Vol. 2 : Iss. 2 , Article 3. DOI: 10.47893/IJMIE.2012.1073

Available at: https://www.interscience.in/ijmie/vol2/iss2/3

This Article is brought to you for free and open access by the Interscience Journals at Interscience Research Network. It has been accepted for inclusion in International Journal of Mechanical and Industrial Engineering by an authorized editor of Interscience Research Network. For more information, please contact sritampatnaik@gmail.com. 


\title{
Design and Analysis of Water Motor Vehicle with Electrolysis Process
}

\author{
ABHISHEKH KUMAR \& ANKIT JAIN \\ ${ }^{1,2}$ JIT Borawan (M.P.), S.S.S.I.S.T., Sehore (M.P.) \\ E-mail:ydvabhishek@gmail.com, ankit_mech86@rediffmail.com
}

\begin{abstract}
In our vehicle, the power plant (engine) will use hydrogen as well as gasoline for all the various functions which the vehicle or any part of it, may be called upon to perform. If by chance there is shortage of hydrogen, our vehicle will switch over to gasoline mode. We chose water because water is a binary compound that occurs at room temperature and is widely used as solvent. Hence we decided to separate out hydrogen and oxygen from $\mathrm{H}_{2} \mathrm{O}$. And also it will make our vehicle echo friendly. As hydrogen is a non metallic univalent element which is highly flammable diatomic gas whereas oxygen is a non-metallic bivalent element which is non flammable diatomic gas, we will use hydrogen in order to provide the necessary energy to run our vehicle. Because of hydrogen's high flammability and low ignition energy, we are using Mazda's Winkle engine in order to avoid pre ignition of hydrogen. Hydrogen will be obtained with the help of electrolysis process and this process will be done with the help of solar energy. We have designed our vehicle to run on water, because after studying about electrolysis process we concluded that ocean water would increase the rate of electrolysis. Hence we decided to run our vehicle on.
\end{abstract}

\section{INTRODUCTION}

\subsection{Main challenges}

The serious problems that are affecting the development of hydrogen vehicles are; hydrogen storage, the high reactivity of hydrogen, the cost and methods of hydrogen fuel production, consumer demand and the cost of changing the infrastructure to accommodate hydrogen vehicles. The concerns surrounding the storage of hydrogen are a major issue. Hydrogen must be stored at extremely low temperatures and high pressure. A container capable of withstanding these specifications is larger than a standard gas tank. Hydrogen storage could be viewed as a problem by consumers. Hydrogen is extremely reactive. Hydrogen is combustible and flammable. The Hindenburg disaster, where hydrogen filled blimp exploded and many people died, has caused a fear of hydrogen. Current production of hydrogen takes a lot of energy. If we have to burn fossil fuels to make hydrogen, what have we really gained? New cleaner energy technology or hydrogen production methods will need to be developed for hydrogen vehicles to make sense. Another problem for hydrogen fuel is consumer demand and the cost to change all gasoline filling stations and vehicle production lines into hydrogen. The problem is like "the chicken or the egg?". The major car companies will not start to produce hydrogen cars until there is consumer demand. Why would a person pay for an expensive car that doesn't have fuel when gas is so cheap? Oil companies will not build filling stations until the hydrogen cars are on the market. There has been reluctance on the part of the oil companies to develop a technology where fossil fuels are not needed. Currently the companies control all of the transportation fuel distribution. There is no incentive to develop an expensive technology that would compete against the fossil fuel technology that oil company's control. When we started our project we concentrated our mind on engine and hydrogen storage tank. Many considerations were made to check the cost but we think that researchers should come up to give something green to our society 1.2 Proposed solution

The purpose of this study was to develop an understanding of the electrolytic hydrogen production technology today. However, it may be years before this technology becomes an important player in the transportation fuel arena. The future costs of hydrogen production via electrolysis need to be researched and analyzed. If all ICE motors (Internal Combustion Engines) were converted to burn hydrogen and oxygen in the water, as fuel to propel our cars, trucks, semi's etc., we would no longer need gas stations, oil tankers, refineries, SMOG and war. The only problem would be that the large Oil Corporations would go under and SMOG would leave the planet for good. The Ozone would get healed and we would survive. God will then once again smile down on the Earth, instead of letting the powers to be, destroy it. If we stopped producing SMOG, the ozone and global warming and greenhouse effects would go away. In order for electrolysis to produce low cost hydrogen, low cost electricity must be available. Scenarios need to be researched under which electricity could be available to forecourt sized electrolysers' for prices equal to or less than current industrial electricity prices. One of the scenarios that may be of particular interest in longer-term models is distributed hydrogen generation and its relationship to distributed power. Oxygen by-product credits are another way electrolytic hydrogen is also made more economical. A better understanding of the current and future oxygen market is needed to justify such a credit.

First we calculated, how much amount of hydrogen is available in one gallon water 
1 gallon Water $=1,864$ gallons Hydrogen

\section{Introduction of all technology and processes used}

2.1 Hydrogen and gasoline engine

Technical advancements over the past decade have necessitated precise need of changing our current power plant (engine) for the sake of our planet. A conventional engine which uses gasoline and diesel as fuel are leaving carbon footprints in the environment. We are using hydrogen engine, hydrogen engines burn fuel in the same manner that gasoline engines do. Hydrogen is extremely flammable, requiring far less energy to ignite than gasoline. Due to this property, hydrogen in an ordinary reciprocating engine is very susceptible to abnormal combustion during the intake stroke due to the high temperature of the spark plugs. Because of this, achieving ideal combustion becomes extremely difficult. The power output of a direct injected hydrogen engine vehicle is $20 \%$ more than for a gasoline engine vehicle and $42 \%$ more than a hydrogen engine vehicle using a carburettor. But hydrogen has very low ignition energy. The amount of energy needed to ignite hydrogen is about one order of magnitude less than that required for gasoline. This enables hydrogen engines to ignite lean mixtures and ensures prompt ignition. Unfortunately, the low ignition energy means that hot gases and hot spots on the cylinder can serve as sources of ignition, creating problems of premature ignition and flashback. Preventing this is one of the challenges associated with run-ning an engine on hydrogen. Premature ignition is a much greater problem in hydrogen fuelled engines than in other IC engines, because of hydrogen's lower ignition energy. After analyzing different types of engine we found that Wankel engine is resistant to preignition and will run on lower-octane rating gasoline than a comparable piston engine. This is because of the shape of the Wankel combustion chamber Mazda has developed Wankel engines that burn hydrogen. Hence we decided to use this engine because of so many advantages it is having. Power output of a wankel engine is generally higher than that of a four-stroke piston engine of similar physical dimensions and weight. Wankel engines that operate within their original design parameters are almost immune to catastrophic failure. A Wankel engine that loses compression, cooling or oil pressure will lose a large amount of power, and will die over a short period of time; however, it will usually continue to produce some power during that time. Piston engines under the same circumstances are prone to seizing or breaking parts that almost certainly results in major internal damage of the engine and an instant loss of power. Due to a $50 \%$ longer stroke duration compared to a four-cycle engine, there is more time to complete the combustion. Mazda's wankel engineThe twin-rotor Wankel engine is configured to run on either hydrogen or gasoline. The hydrogen tank, with a capacity of 110 litres at 350 bar stores up to 2.4 kilograms of hydrogen and is fitted in addition to the 61 litre gasoline tank. In the rotary engine, the intake chamber is separated from the combustion chamber. This minimizes the risk of abnormal combustion, and makes the rotary engine very suitable for burning hydrogen fuel.

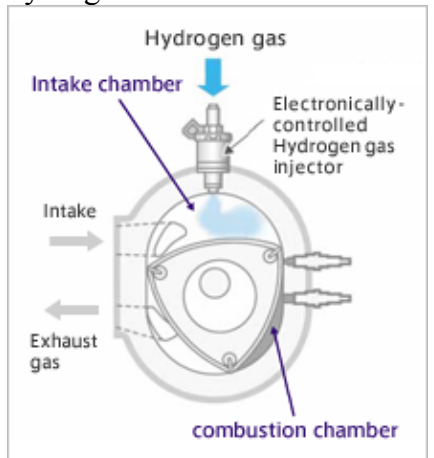

Figure showing Mazda's Winkle engine which uses hydrogen as well as gasoline as fuel. In addition, by implementing Mazda's direct injection technology, the hydrogen rotary engine achieves even better combustion. A huge 110-litre hydrogen tank fills the entire boot area and the boatful of hydrogen extends its range by a further $100 \mathrm{~km}$. Major specifications of Mazda's twin rotor winkle engine-

Name Mazda RX-8 Hydrogen RE

Engine

Type RENESIS hydrogen rotary engine (dual-fuel system)

Fuel Hydrogen and gasoline

Maximum output In hydrogen mode: 80 kW (109 PS)

In gasoline mode: $154 \mathrm{~kW}$ (210 PS)

Maximum torque In hydrogen mode: $140 \mathrm{Nm}$ (14.3

In gasoline mode: $222 \mathrm{Nm}(22.6 \mathrm{kgm})$

Gearbox 5-speed manual

gearbox

Maximum speed

$170 \mathrm{~km} / \mathrm{h}\left(\mathrm{H}_{2}-\right.$ operation

2.2 Solar panel

Water-splitting solar panels are having important advantages over existing technologies in terms of hydrogen production. Right now, the primary way to make hydrogen is to separate it from natural gas, a process that generates carbon dioxide and undercuts the main motivation for moving to hydrogen fuel-cell vehicles: ending dependence on fossil fuels. The current alternative is electrolysis, which uses electricity to break water into hydrogen and oxygen, with the two gases forming at opposite electrodes. Although electrolysis is costly, it can be cleaner if the source of the electricity is wind, sun, or some other carbon-free source. But we thought if the source of the electricity is sun, it would be much more efficient to use solar energy to produce hydrogen by a photochemical process inside the cell itself. 


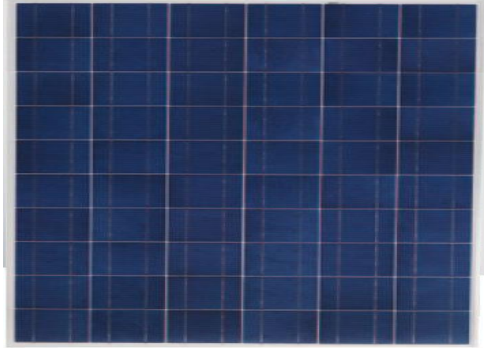

Image showing CS6X-295M

Number of panels which we require is about

Dimension of a single panel is $1954.0 \times 982.0 \times$ $40.0 \mathrm{~mm}(38.7 \times 76.9 \times 1.6$ inch $)$

Weight of a single panel is $28.0 \mathrm{Kg}(61.7 \mathrm{lbs})$

Defects \& Workmanship Warranty Period is of 6.0 Years

\subsection{Electrolysis}

When a direct electric current is passed through an electrolyte (an aqueous solution of a salt), chemical reactions take place at the contacts between the circuit and the solution. This process is called electrolysis. The combination of container, electrodes and electrolyte constitute the electrolytic cell. An electrical power source is connected to two electrodes, or two plates (typically made from some inert metal such as platinum or stainless steel) which are placed in the water. Hydrogen will appear at the cathode (the negatively charged electrode, where electrons enter the water), and oxygen will appear at the anode (the positively charged electrode).

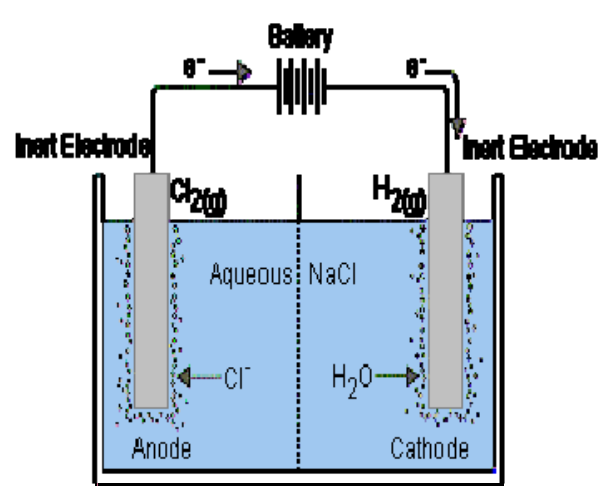

Hydrogen gas production is directly proportional to the current draw only. The ratio, by volume, of hydrogen to oxygen, is exactly $2: 1$.

We are following laws-

Faraday's law of first electrolysis-

"The amount of any substance deposited, evolved, or dissolved at an electrode is directly proportional to the amount of electrical charge passing through the circuit."

Faraday's law of second electrolysis-

"The mass of different substances produced by the same quantity of electricity are directly proportional to the molar masses of the substances concerned and inversely proportional to the number of electrons in the relevant half-reaction."

Equations taking place in this process are as follows-

$$
\begin{array}{lr}
\text { 1.Anode (oxidation): } & 2 \mathrm{H}_{2} \mathrm{O}(\mathrm{l}) \rightarrow \\
\mathrm{O}_{2}(g)+4 \mathrm{H}^{+}(a q)+4 \mathrm{e}^{-} & \\
\text {2.Reduction at cathode: } & 2 \mathrm{H}^{+}(a q)+ \\
2 \mathrm{e}^{-} \rightarrow \mathrm{H}_{2}(g) & \\
\text { 3.Net } & 2 \mathrm{H}_{2} \mathrm{O}(\mathrm{l}) \rightarrow \\
2 \mathrm{H}_{2}(\mathrm{~g})+\mathrm{O}_{2}(\mathrm{~g}) &
\end{array}
$$

Electrode- An electrode is an electrical conductor used to make contact with a non-metallic part of a circuit (e.g. a semiconductor, an electrolyte or a vacuum).

We are using inert electrodes for electrolysis (made of platinum or stainless steel).

Electrode specifications

Wire (Round Cross-Section)

Dimensions - $137 \mathrm{~mm}$ (5 3/8 inches) is the overall height.

Wire diameter $2.4 \mathrm{~mm}$; dia. of insulated portion $3.1 \mathrm{~mm}$.

Its shape is bent at one end like a candy cane.

Block diagram showing entire grid of the system which is used in the vehicle

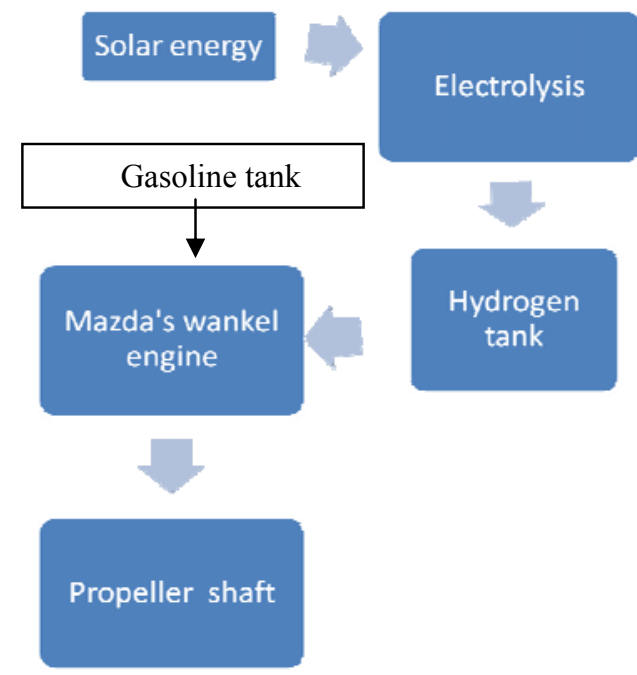

Solar energy from sun is used by solar plates which then are used to start electrolysis, electrolysis process separates out hydrogen from water and this hydrogen is used to run Winkle engine which in turn will provide motion to our vehicle. 


\section{Advantages}

Switching to vehicles powered by hydrogen fuel instead of fossil fuels will provide significant health and environment benefits, save life and money, according to a new study released on Thursday. Mark Jacobson, an associate professor at Stanford University, said that converting all vehicles to hydrogen vehicles may improve air quality, health and climate significantly. Jacobson and colleagues' paper was published in the June 24 issue of journal Science. Most benefits would result from eliminating current vehicle exhaust. Wind and natural gas hydrogen vehicles offer the greatest potential health benefits and could save 3,700 to 6,400 lives in the United States annually. And among all HFCV types, the wind HFCVs, which means the hydrogen is produced through wind electrolysis, should benefit climate most, the researchers found. Earlier studies have modelled the effects of hydrogen leakage or reduced emission on global troposphere and stratospheric chemistry, but no research has examined the effect on urban pollution or health of establishing a hydrogen economy. Furthermore, no study has examined the likely effects of this switch on aerosol particles, which have a large impact on climate and are the deadliest components of air pollution. But in this new research, the Stanford group used a computing model to examine the possible effects on ambient gas, particle concentrations, and estimated health and climate costs if replacing all US fossil-fuel vehicles with HFCVs. They compared the benefits of producing hydrogen by steam reforming of natural gas, wind and solar electrolysis and coal gasification, and found most of HFCVs' benefits arose from eliminating current vehicle exhaust. An all-HFCV fleet would hardly affect troposphere water vapour concentrations, the researchers said. Conversion to coal HFCVs may improve health but would damage climate more than fossil/electric hybrids. Fuel cell vehicles using hydrogen produced by wind and solar offer the greatest potential health benefits, and could save 3, 700 to 6,400 lives annually in the United States by reducing air pollution. And ultimately, hydrogen produced from wind would cost between 1.12 and 3.20 dollars per gallon in the United States. This sum is lower than gasoline price, although the estimates do not include the infrastructure costs of converting to hydrogen, according to the study.

\section{Limitations}

There are limitations in using photovoltaic (PV) cells for vehicles:

- Power density: Maximum power from a solar array is limited by the size of the vehicle and area that can be exposed to sunlight. While energy can be accumulated in batteries to lower peak demand on the array and provide operation in sunless conditions, the battery adds weight and cost to the vehicle. The power limit can be mitigated by use of conventional electric cars supplied by solar (or other) power, recharging from the electrical grid.

- Cost: While sunlight is free, the creation of $\mathrm{PV}$ cells to capture that sunlight is expensive. Costs for solar panels are steadily declining $(22 \%$ cost reduction per doubling of production volume).

- Design considerations: Even though sunlight has no lifespan, PV cells do. The lifetime of a solar module is approximately 30 years. Standard photovoltaic often come with a warranty of $90 \%$ (from nominal power) after 10 years and $80 \%$ after 25 years. Mobile applications are unlikely to require lifetimes as long as building integrated PV and solar parks. Current PV panels are mostly designed for stationary installations. However, to be successful in mobile applications, PV panels need to be designed to withstand vibrations. Also, solar panels, especially those incorporating glass have significant weight. To be useful, the energy harvested by a panel must exceed the added fuel consumption caused by the added weight.

5. Applications of project

Vehicle or vessel is a device that is designed or used to transport people or cargo. Most often used vehicles are bicycles, cars, motorcycles, trains, ships, boats, and aircraft. As the vehicle we are designing will run on water, it can be used as a cargo ship. And also it can be used for those who want to spend their holidays on an island.

Future Enhancement We are thinking to merge the current system with wind source, so that we can use wind as an alternate source in order to start electrolysis for the production of hydrogen

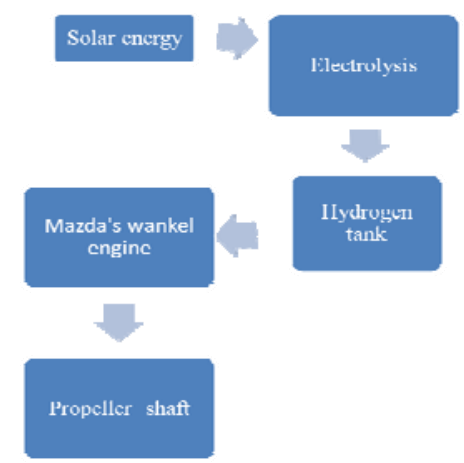

We are thinking to enhance our project by designing a system which will help the vehicle to run on road also. 


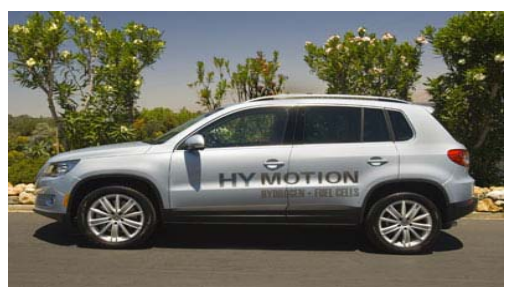

\section{REFERENCES}

B.H. Khan (Non- conventional energy)

Cenjal (thermodynamics)

D. Ray (non-conventional energy)

Heat \& Mass Transfer (P K Nag)

http://www.solardesigntool.com

http://www.solardesigntool.com

http://www.motortrend.com

http://www.ultimatecarpage.com

http://www.goauto.com

http://www.mazda.com

http://www.hydrogen-motors.com

http://www.energyboom.com 